\title{
Model parameterization to simulate and compare the PAR absorption potential of two competing plant species
}

\author{
Jörg Bendix • Brenner Silva • Kristin Roos • \\ Dietrich Otto Göttlicher • Rütger Rollenbeck • \\ Thomas Nauß • Erwin Beck
}

Received: 27 February 2009 /Revised: 11 October 2009 / Accepted: 11 October 2009/Published online: 25 November 2009

(C) The Author(s) 2009. This article is published with open access at Springerlink.com

\begin{abstract}
Mountain pastures dominated by the pasture grass Setaria sphacelata in the Andes of southern Ecuador are heavily infested by southern bracken (Pteridium arachnoideum), a major problem for pasture management. Field observations suggest that bracken might outcompete the grass due to its competitive strength with regard to the absorption of photosynthetically active radiation (PAR). To understand the PAR absorption potential of both species, the aims of the current paper are to (1) parameterize a radiation scheme of a two-big-leaf model by deriving structural (LAI, leaf angle parameter) and optical (leaf albedo, transmittance) plant traits for average individuals from field surveys, (2) to initialize the properly parameterized radiation scheme with realistic global irradiation conditions of the Rio San Francisco Valley in the Andes of southern Ecuador, and (3) to compare the PAR absorption capabilities of both species under typical local weather conditions. Field data show that bracken reveals a slightly higher average leaf area index (LAI) and more horizontally oriented leaves in comparison to Setaria. Spectrometer measurements reveal that bracken and Setaria are characterized by a similar average leaf absorptance. Simulations with the average diurnal course of incoming solar radiation (1998-2005) and the mean leaf-sun geom-
\end{abstract}

J. Bendix $(\bowtie) \cdot$ B. Silva $\cdot$ D. O. Göttlicher $\cdot$ R. Rollenbeck $\cdot$

T. Nauß

Laboratory for Climatology and Remote Sensing,

Faculty of Geography, University of Marburg,

Deutschhausstr. 10,

35032 Marburg, Germany

e-mail: bendix@staff.uni-marburg.de

K. Roos $\cdot$ E. Beck

Plant Physiology, Faculty of Biology, Chemistry and Geosciences,

University of Bayreuth,

95447 Bayreuth, Germany etry reveal that PAR absorption is fairly equal for both species. However, the comparison of typical clear and overcast days show that two parameters, (1) the relation of incoming diffuse and direct irradiance, and (2) the leaf-sun geometry play a major role for PAR absorption in the twobig-leaf approach: Under cloudy sky conditions (mainly diffuse irradiance), PAR absorption is slightly higher for Setaria while under clear sky conditions (mainly direct irradiance), the average bracken individual is characterized by a higher PAR absorption potential. ( $74 \mathrm{MJ} \mathrm{m}^{-2}$ year ${ }^{-1}$ ). The latter situation which occurs if the maximum daily irradiance exceeds $615 \mathrm{~W} \mathrm{~m}^{-2}$ is mainly due to the nearly orthogonal incidence of the direct solar beam onto the horizontally oriented frond area which implies a high amount of direct PAR absorption during the noon maximum of direct irradiance. Such situations of solar irradiance favoring a higher PAR absorptance of bracken occur in $\sim 36 \%$ of the observation period (1998-2005). By considering the annual course of PAR irradiance in the San Francisco Valley, the clear advantage of bracken on clear days ( $36 \%$ of all days) is completely compensated by the slight but more frequent advantage of Setaria under overcast conditions (64\% of all days). This means that neither bracken nor Setaria show a distinct advantage in PAR absorption capability under the current climatic conditions of the study area.

Keywords Southern bracken - Setaria sphacelata $\cdot$ PAR absorption · Two-big-leaf approach · Andes · Ecuador

\section{Introduction}

The Ecuadorian Andes are one of the major hot spots of vascular plant diversity worldwide (Barthlott et al. 2007). 
At the same time, the natural forests in Ecuador suffer from the highest deforestation rate $(1.2 \%$ per year $)$ in Latin America (FAO 2001). In the eastern Cordillera, large areas of tropical forest have been cleared by slash and burn for gaining pastureland. On slopes of moderate inclination, the Sorghum-like tillering Setaria sphacelata is grown in monocultures. Our previous studies on Setaria pastures have shown that the current mode of pasture management favors the growth of an extremely aggressive weed, the tropical bracken fern Pteridium arachnoideum (Hartig and Beck 2003). This process is particularly prominent in the lower parts of the Rio San Francisco valley $<2,400 \mathrm{~m}$ asl (Fig. 1) where large areas $(\sim 68 \%)$ of former pastures have been abandoned due to bracken infestation and the concomitant supersession of the pasture grass (Beck et al. 2008a; Göttlicher et al. 2009). Unfortunately, the loss of pasture usability boosts the land use pressure on the remaining natural forest, threatening its unique biodiversity.
Consequently, bracken should be effectively controlled to retain pasture productivity, but to date, the reason for its competitive strength is not well understood. Some investigations suggest that spreading and growth of bracken seems to be stimulated by burning (e.g., Page 1986; Cruz et al. 2009). Other studies on bracken in England and Mexico (Marrs et al. 2000a, b; Schneider 2004) point out that bracken fronds cast shadow on underlying plants, thus outcompeting understorey vegetation like grass tufts. Field observations in the study area show that bracken accelerates growth after burning which suggests that the shading of the pasture grass by the fast emerging fronds seems to boost the dominance of bracken after recurrent burning increasingly (Hartig and Beck 2003). However, final evidence is still lacking. Numerical simulation models encompassing radiative transfer approaches (e.g., Pronk et al. 2007) might help to unveil the importance of frond shadow for the competitive strength of bracken in the study area. For spatial

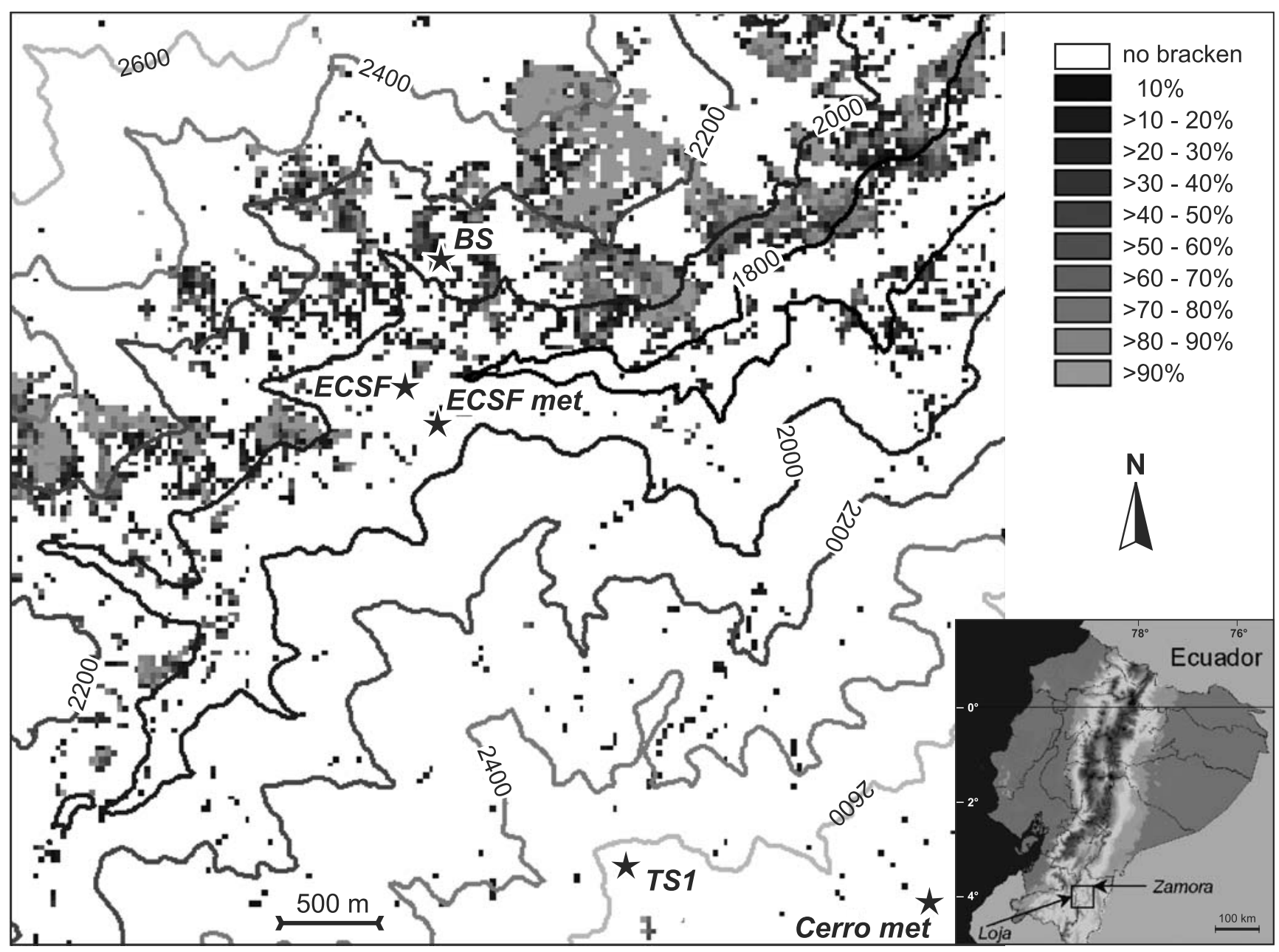

Fig. 1 The research area showing fractional cover by southern bracken as derived from Landsat TM data with the probability guided spectral unmixing technique (Göttlicher et al. 2009); BS experimental bracken site and micrometeorological station, ECSF Estación Científica San
Francisco, ECSF met Meteorological station of the Estación, TS1 and Cerro met are meteorological stations located at 2,660 and 3,180 m asl, respectively. Grey shades indicate different bracken coverage per pixel, white means bracken-free pixel 
applications, grid-cell based two-big-leaf models have been proven to be computationally efficient (Wang and Leuning 1998) with good accuracy compared to more complex multilayer models (Zhang et al. 2001). The first research question in order to estimate the competitive strength of species with regard to radiation available for plant growth is if the two competing species reveal different PAR (photosynthetically active radiation) absorption potentials.

Consequently, the main objective of the current paper is to compare the PAR absorption potential of the two competing plant species, Setaria sphacelata and Pteridium arachnoideum, as the basis for future research on growth competition modeling using a numerical vegetation growth model. The comparison is conducted by applying the radiation scheme of a state of the art grid-based two-bigleaf model (Dai et al. 2004; Thornton and Zimmermann 2007). Because the model is normally operated with default parameters for broad groups of plant functional types (broadleaf trees, grass, etc.), a proper parameterization with structural and optical plant traits is required to adapt the scheme to the competing species (e.g., Larocque 2002; Wang et al. 2006b; Boulain et al. 2007). With regard to structural plant traits, Lappi and Stenberg (1998), for instance, stressed that simulation of PAR interception/ absorption is highly dependent on the relation of leaf orientation and solar geometry.

Thus, the second goal of the current study is to adapt the radiation scheme to the two species of interest by providing the required structural and optical plant traits based on extensive field surveys. The properly parameterized scheme is then used to simulate the PAR absorption capabilities of both species under the varying and realistic illumination conditions of the study area in the Andes of southern Ecuador.

\section{Materials and methods}

Study area and data

The current investigation is part of a multidisciplinary ecological research project. The study area comprises parts of the deeply incised valley of the Rio San Francisco in the eastern range of the South Ecuadorian Andes in the vicinity of the research station Estación Científica San Francisco (ECSF, 3 $3^{\circ} 8^{\prime} 18^{\prime \prime} \mathrm{S}, 79^{\circ} 4^{\prime} 45^{\prime \prime} \mathrm{W}$, alt. 1,860 m asl; Fig. 1). The station is situated between the provincial capitals of Loja in the inner-Andean basin west of the main cordillera and Zamora in the foothills of the eastern Andes. The core area displayed in Fig. 1 encompasses an altitudinal gradient from 1,800 to $3,200 \mathrm{~m}$ asl. A detailed description is given in Bendix et al. (2006a) and Beck et al. (2008b). The climate of the Rio San Francisco valley is perhumid
(Richter 2003; Bendix et al. 2008a, b). Important for the radiation conditions is the high cloud frequency over the entire year, especially at higher altitudes (Bendix et al. $2006 \mathrm{~b}, 2008 \mathrm{c}$ ). While the north-facing slopes of the valley are covered by a species-rich natural mountain forest (Brehm et al. 2008), the south-facing slopes have been cleared by slash and burn for the acquisition of pasture land where large portions of the lower terrain between 1,800 and $2,500 \mathrm{~m}$ are already infested or completely overgrown by bracken (Fig. 1).

Long-term meteorological data for the current study were available from the ECSF meteorological station located at 1,960 $\mathrm{m}$ asl (ECSF met in Fig. 1), the altitudinal level of the bracken-infested pastures. At this station, global radiation has been measured since 1998. Monthly means of global radiation from 1998-2005 as presented in Bendix et al. (2008a) were used in this study. Additionally, an experimental site (BS in Fig. 1) consisting of ten $10 \times 10 \mathrm{~m}$ plots with different fractions of bracken and Setaria was established in 2007 in the vicinity of the main meteorological station (ECSF met). The site encompasses a micrometeorological station that measures global radiation at 5-min temporal resolution. Global radiation at both stations was measured with the Kipp \& Zonen CM3 pyranometer for the entire solar spectrum (spectral range 305-2,800 nm).

\section{Radiation scheme}

To calculate PAR absorption by bracken and Setaria, the radiation scheme of the two-big-leaf approach of Dai et al. (2004) was applied. Generally, big-leaf approaches describe the water and gas exchange of vegetation in a simple way where the canopy is treated as one layer with a single physiological and aerodynamic resistance to water $/ \mathrm{CO}_{2}$ transfer. A big-leaf model generally encompasses (1) a radiation scheme as discussed in this study, (2) a leaf model accounting for the interaction of conductance and photosynthesis and the response of stomata to water vapor pressure deficit and available soil water, and (3) a parameterization of radiative conductance to solute the leaf energy balance equation (Wang and Leuning 1998). The two-big-leaf extension separates the whole canopy leaf area into sunlit and shaded leaf portions and the canopy-average PAR values are estimated for each leaf portion, which needs the application of radiative transfer calculations between the sunlit and shaded leaf fraction and the underlying soil (Zhang et al. 2001). Species are represented in a two-bigleaf models as a single plant with one sunlit and one shaded leaf. Average traits (e.g., leaf albedo) that are representative for the species are assigned to the model plant.

It is presupposed that the sunlit leaf receives both diffuse and direct radiation while the shaded leaf receives diffuse light only. 
The photon transport among the atmosphere, the sunlit and shaded leaf area, and the ground is calculated by using the two-stream approximation with single scattering and uniform leaf orientation as presented in Dickinson (1983) and Sellers (1985). This module is the central part of the radiation scheme of Dai et al. (2004) which was used in the current study. With regard to canopy albedo, Myneni et al. (1992) showed that the accuracy of similar 1D radiative transfer schemes is adequate in comparison to more complex and computational expensive 3D approaches. Also, the prediction of PAR provided reasonable values when compared with a more complex multi-layer model (Zhang et al. 2001).

The numerical solutions and all relevant equations of the radiation scheme used in this study are already published in Dai et al. (2004) and will not be repeated here in detail.

In the current study, the scheme is initialized by global radiation data at hand so that the decomposition for the direct, diffuse and PAR fraction is necessary.

On the plant level, the study focused on an average individual of bracken and the pasture grass Setaria. PAR absorption of the two species is strongly dependent on their functional traits that have to be derived from field observations to parameterize the radiation scheme properly. The first plant trait (or model parameter) of importance is the average leaf angle because it determines the leaf orientation to the sun and thus radiation absorption. In the radiation scheme, the average leaf projection $G(\mu)$ is used which is derived from (Dai et al. 2004):

$$
\phi_{2}=0.877 \cdot\left(1-2 \cdot \phi_{1}\right)
$$

where $\mu$ is the cosine of the solar zenith angle, $\phi_{1}$ and $\phi_{2}$ are coefficients from the Ross-Goudriaan function (see Sellers 1985) and $\chi$ represents the leaf angle distribution ( $1=$ horizontal, $-1=$ vertical, $0=$ spherical leaf angle distribution) that have to be measured for representative individuals of bracken and Setaria in the experimental plots. It is obvious that the leaf orientation in relation to the solar angle determines drop shadow on shaded leaves and thus, the sunlit and shaded fractions of leaf area (see Dai et al. 2004).

The second important trait is the spectral leaf albedo because it determines the proportion of solar radiation remaining available for absorption and transmission. For instance, the direct incident beam radiation absorbed by leaves at canopy depth $\times$ per unit leaf area index $L$ (excluding scattering) is calculated in the scheme as (Dai et al. 2004):

$I_{l b}=(1-\omega) \cdot k b \cdot \exp (-k b \cdot x L) \cdot I_{b 0}$

where $I_{b 0}$ is the incident direct beam radiation above the canopy, $k b$ the direct beam extinction (see Dai et al. 2004) and the leaf scattering coefficient $\omega$ is:

$\omega=\alpha+\tau$

with $\alpha$ is the spectral leaf albedo (second parameter) and $\tau$ the spectral leaf transmittance as the third important functional trait, determining the transmission of radiation to the shaded leaf area fraction and the underlying bare soil. Consequently, both optical parameters have to be derived from field measurements of representative individuals of bracken and Setaria. Equation (2) also uses the leaf area index that is available for PAR absorption. Thus, also the average leaf area index is a model parameter that has to be derived from field observations.
On the soil level, soil spectral albedo has to be measured because it determines the backscattered direct and diffuse radiation fractions in direction of the green phytoelements which are generally available for PAR absorption, increasing with soil albedo (Nouvellon et al. 2000).

\section{Decomposition of global radiation data}

The two-big-leaf scheme requires the diffuse and direct fractions of solar radiation as input. Because only global radiation was measured at the meteorological stations, we used an empirical decomposition function to partition incident solar radiation in its diffuse and direct fractions. Generally, such functions are based on the diffuse fraction of radiation $\left(k^{\prime}\right)$ and the clearness index $(k t)$. The clearness index $(k t)$ is the ratio of incoming radiation at the earth surface $\left(I_{0}\right)$ to the radiation at the top of the atmosphere on a horizontal surface $\left(I_{T O A}\right)$.

$k t=I_{0} / I_{T O A}$

Diffuse $I_{d 0}$ and direct $I_{b 0}$ radiation incident above the canopy is then derived by:

$I_{d 0}=I_{0} \cdot k^{\prime}$

$I_{b 0}=I_{0} \cdot\left(1-k^{\prime}\right)$

where $I_{0}$ is the incident global radiation above the canopy.

Empirical radiation decomposition functions are generally more or less site dependent. To find the most appropriate function for the San Francisco valley, six published functions are examined. Erbs et al. (1982) used data sets from U.S. 
locations to formulate a piecewise regression function that has been widely and successfully used in other parts of the world (Elminir 2007). A modified version of Erbs function was recently proposed by Wang et al. (2006a). Two versions of a function of Boland et al. $(2001,2008)$ for Australia yields lower fractions of diffuse radiation at a high clearness index, which could principally apply to situations in high elevations in the absence of clouds. A function taking annual seasonality into account was determined for southeast Brazil by Oliveira et al. (2002). Maduekwe and Chendo (1994) presented a numerical solution with solar elevation as a second predictor for the diffuse fraction. Figure 2a shows the long-term averaged (1998-2005) daily course of diffuse radiation calculated from the long-term incident global radiation at the ECFS meteorological station. The diffuse fraction as a function of the clearness index is also displayed (Fig. 2b). The data show that the fraction of diffuse radiation in the study area is generally high. In the early morning and late afternoon hours, almost the only radiation present is diffuse, while around noon, direct irradiance accounts for approximately one third. The dominance of diffuse radiation is mainly due to the overall high cloudiness of $\sim 80 \%$ over the day and the year in the San Francisco valley (Bendix et al. 2006b, 2008c).

The function of Boland et al. (2001) (BSL), with the solar apparent time as predictor (BSLa at 0800 and BSLb at 1700 hours in Fig. 2b), results in relatively strong deviations in the afternoon. Oliveira's function (OESM), which summarizes the winter (OESMa) and summer (OESMb) regressions, gives the lowest diffuse radiation fraction. The other four decomposition functions which comprise Boland et al. (2008) (BRB) and Erbs et al. (1982) (EKD) give more or less identical daily courses. The difference between the mean of these functions and Oliveira's solution varies between -1 and $+22 \%$ of the global radiation. For the current study, we used the modified Erbs' function (EKD2) because it considers the increase of diffuse radiation on lower solar elevation (see Fig. 2b where EKD2 is calculated for a solar elevation of $15^{\circ}$ ). The diffuse fraction $k^{\prime}$ is calculated in a two-step procedure as follows:

$k=\left\{\begin{array}{l}1-0.09 \cdot k t \quad 0 \leq k t \leq 0.22 \\ 0.9511-0.1604 \cdot k t+4.388 \cdot k t^{2}-16.638 \cdot k t^{3}+12.336 \cdot k t^{4} \quad 0.22<k t \leq 0.8 \\ 0.165 \quad 0.8 \leq k t \leq 1 .\end{array}\right.$

$k^{\prime}=\frac{k}{(1-k) \cdot \mu+k}$

where $k^{\prime}$ is the diffuse fraction of radiation modified due to solar geometry with the cosine of solar zenith angle $\mu$.

To obtain the PAR fraction from global radiation, a conversion factor of 0.48 is generally multiplied by $I_{0}$, but Zhang et al. (2000) and Lee and Hernández-Andrés (2005) showed that the PAR fraction varies particularly in the presence of clouds. A slight increase of the PAR fraction from clear to cloudy sky due to larger forward scattering was observed by Papaioannou et al. (1993) and Roderick et al. (2001). Tsubo and Walker (2005) considered clouds by applying the clearness index as predictor for the PAR fraction. Consequently, this function addresses best the high cloud frequency in the San Francisco valley and is therefore used in the current study:

$\mathrm{I}_{\mathrm{PAR}}=\left(0.121 \cdot k t^{2}-0.334 \cdot k t+0.613\right) \cdot I_{0}$

Field observations of plant and soil parameters

The two required structural plant parameters, the leaf area index and the leaf to ground angles, were measured with a LICOR LAI-2000 plant canopy analyzer. Leaf area index and leaf angles were taken for representative Setaria and bracken individuals. A total of 24 measurements for each species were conducted between October 2007 and March 2008 on the experimental site (BS in Fig. 1). Canopy leaf angle was determined as mean tilt angle (MTA) (see Peri et al. 2003) that, however, is in good agreement with directly derived mean leaf angles (Antunes et al. 2001). Mean tilt angle orientation of measured foliage is converted to the leaf angle parameter $\chi$ (Eq. 1) by:

$\chi=\cos (M T A)-\sin (M T A)$

The two optical plant traits (leaf albedo and transmission) and soil albedo were measured with the field spectrometer Tec5 HandySpec Field 14 during late 2007 and early 2008. The instrument encompasses a Zeiss MMS 1 NIR enhanced $(310-1,100 \mathrm{~nm}, \mathrm{~d} \lambda=3.3 \mathrm{~nm})$ and a Zeiss Plangitter PGS NIR $1.7(960-1,690 \mathrm{~nm}, \mathrm{~d} \lambda=1.5 \mathrm{~nm})$ sensor. For reflection measurements, fresh leaves of representative individuals were collected and inserted in a wooden frame to normalize the measurements to a leaf area index of 1 . Average values were calculated from three measurements of each species. Topsoil samples were taken from the experimental bracken site, representing the soil under bracken and grass. Spectral integration of the data was conducted for PAR $(<700 \mathrm{~nm})$ and NIR ( $\geq 700 \mathrm{~nm})$. 
a

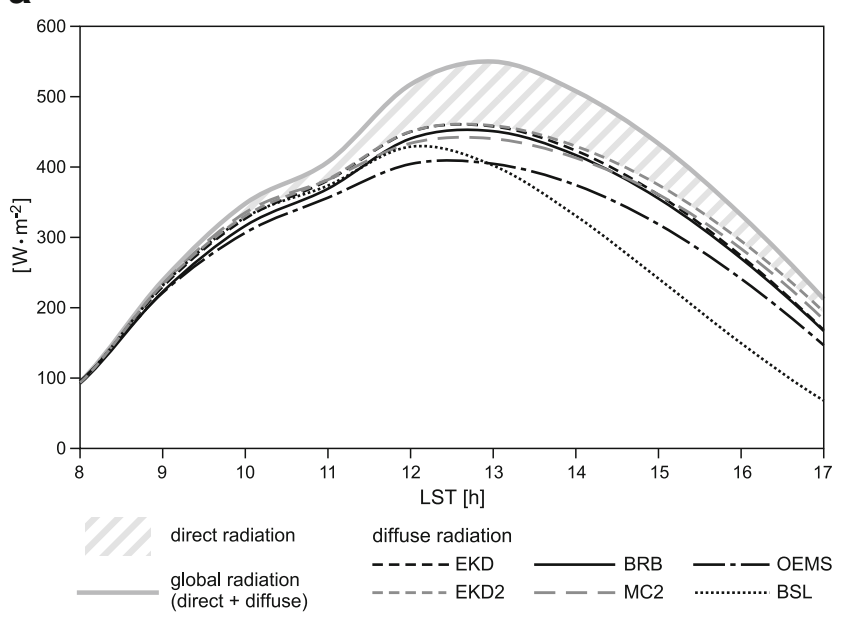

b

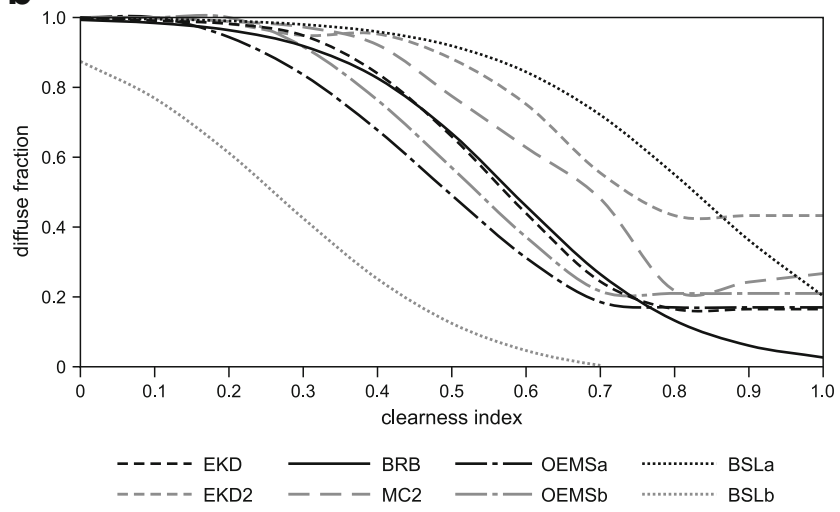

Fig. 2 a Average diurnal course of global and derived diffuse radiation at ECSF met station (1998-2005). b The diffuse fraction from six decomposition functions is also shown as a function of the clearness index (bottom). For abbreviations, see text

\section{Results}

Derived plant and soil traits

The observed values of LAI and $\chi$ for representative individuals of Setaria and bracken are presented in Table 1. They show that LAI and $\chi$ (indicated by the mean tilt angle) differ between the samples and thus, the observation situation. However, the principle of the two-big-leaf approach only permits one average individual per species. Thus, the plants selected in the field survey which are presented in Table 1 are chosen to properly represent an average individual. The calculated average structural plant traits are then assigned to the average Setaria and bracken individual used by the radiation scheme which is applied in the next subsection. The same holds for the optical traits presented in Table 2.

With regard to the field data of structural plant traits presented in Table 1, the average leaf are index of bracken
(2.94) is higher than that of Setaria (2.4). The standard deviation reveals that the LAI of bracken is characterized by a slightly higher variation in comparison to Setaria.

Additionally, Table 1 points to a clear difference in leaf angle orientation towards more vertical leaves for the Setaria tufts and more horizontally oriented leaf blades for bracken where the span of leaf angles is generally higher for bracken than for Setaria. The grass reveals a mean leaf angle of $\sim 59^{\circ}$ and an average leaf angle distribution parameter of $\chi=-0.37$ which clearly confirms the more vertical orientation of the grass stalks. MTA values and the low standard deviation show that the angular distribution of Setaria culms is almost unimodal. With regard to bracken, MTA seems to points to a bimodal distribution. Bracken fronds are composed of a long vertical petiole and a nearly triangular tripinnate lamina. Emerging fronds, whose lamina are still unfolded, have not been included in the study. Unfolding of the leaf blade starts when it turns from a vertical position into an angle between 40 and $50^{\circ}$. During further unfolding of the lamina, the leaf blade approaches a more horizontal orientation (MTA of 0 $8^{\circ}$ ). Because an average fern canopy consists of young and mature leaves, the average individual of the two-big-leaf approach must consider both representations which is warranted by the mean leaf angle parameter of $\chi=0.48$.

The albedo data gathered during our field surveys show that both plant species exhibit a marked red edge spectrum of green vegetation with a slightly enhanced reflectance in the green waveband (Fig. 3).

In contrast, the topsoil reveals the typical, almost linear increase of reflectance towards the near infrared. Bracken contrasts with Setaria by a lower reflectance in the PAR and a higher reflectance in the NIR. Transmittance of bracken fronds is slightly higher than that of Setaria over the whole spectrum. The integrated optical traits for the PAR spectral range $(300-700 \mathrm{~nm})$ as derived from the measurements of the field spectrometer for both species (Setaria and bracken) are presented in Table 2. Average integrated PAR reflectance of Setaria $(11.7 \%)$ is higher than bracken PAR albedo (7.4\%). At the same time, integrated PAR transmittance of Setaria $(1.5 \%)$ is lower in comparison to bracken $(3.7 \%)$, resulting in a slightly higher absorptance of $2.1 \%$ for bracken which might potentially favor bracken with regard to photosynthesis.

\section{Simulated PAR absorption capability}

The first quantity that determines the PAR absorption capacity is the species-specific leaf-sun geometry which is mainly influenced by the average leaf angle parameter from Table 1. Figure 4 demonstrates the changing illumination situation for the average individuals of Setaria and bracken depending on solar elevation in relation to leaf 
Table 1 Leaf area index (LAI) and mean tilt angle (MTA) of 24 representative measurements of Setaria sphacelata and bracken (Pteridium arachnoideum) on the experimental site

\begin{tabular}{|c|c|c|c|c|}
\hline \multirow[t]{2}{*}{ Sample } & \multicolumn{2}{|l|}{ Setaria } & \multicolumn{2}{|l|}{ Bracken } \\
\hline & LAI $\left(\mathrm{m}^{2} \mathrm{~m}^{-2}\right)$ & MTA (deg.) & LAI $\left(\mathrm{m}^{2} \mathrm{~m}^{-2}\right)$ & MTA (deg.) \\
\hline 1 & 1.31 & 58 & 1.38 & 8 \\
\hline 2 & 1.79 & 73 & 1.51 & 40 \\
\hline 3 & 1.32 & 62 & 1.65 & 49 \\
\hline 4 & 1.75 & 60 & 1.41 & 0 \\
\hline 5 & 1.38 & 61 & 1.88 & 8 \\
\hline 6 & 1.76 & 54 & 1.40 & 31 \\
\hline 7 & 1.99 & 57 & 2.17 & 28 \\
\hline 8 & 3.84 & 45 & 2.24 & 46 \\
\hline 9 & 2.42 & 59 & 2.87 & 0 \\
\hline 10 & 3.20 & 59 & 3.21 & 36 \\
\hline 11 & 2.76 & 42 & 2.85 & 0 \\
\hline 12 & 3.95 & 45 & 4.76 & 40 \\
\hline 13 & 1.54 & 76 & 3.53 & 40 \\
\hline 14 & 1.50 & 76 & 4.08 & 42 \\
\hline 15 & 2.42 & 63 & 2.23 & 40 \\
\hline 16 & 3.00 & 65 & 2.60 & 0 \\
\hline 17 & 2.71 & 59 & 5.27 & 41 \\
\hline 18 & 2.04 & 62 & 3.97 & 40 \\
\hline 19 & 1.52 & 75 & 2.65 & 13 \\
\hline 20 & 1.72 & 63 & 3.27 & 37 \\
\hline 21 & 4.34 & 51 & 4.88 & 0 \\
\hline 22 & 3.41 & 57 & 3.95 & 36 \\
\hline 23 & 2.76 & 60 & 3.24 & 0 \\
\hline 24 & 3.11 & 53 & 3.50 & 0 \\
\hline Average & 2.40 & 59.79 & 2.94 & 23.96 \\
\hline $1 \sigma$ & 0.90 & 9.14 & 1.15 & 18.87 \\
\hline Average $\chi$ & & -0.37 & & 0.48 \\
\hline
\end{tabular}

orientation. The sunlit and shaded leaf fractions of bracken with its more horizontally oriented fronds run inversely to Setaria with its more upright leaves. At higher solar elevations $\left(>28^{\circ}\right)$ around noon (i.e., at solar zenith lower than $62^{\circ}$ ) bracken shows a smaller sunlit leaf fraction in comparison to Setaria because the sunlit bracken frond casts shadow on the underlying frond area due to the horizontal frond orientation. In contrast, shadowing around noon is clearly reduced in case of the vertically oriented leaves of Setaria. The situation changes in times of lower sun elevation (morning, evening) when cast shadow is preferentially caused by vertically oriented leaves. Then, bracken is favored in receiving direct radiation.
However, the sunlit and shaded leaf fraction must be scaled by the species-specific leaf area index (Table 1) of the average individuals to complete the view on leaf-sun geometry effects on PAR absorption potential. By doing so, Setaria sunlit leaf area exceeds that of bracken at solar zenith angles $<55^{\circ}$ (Fig. 5). The shift of the inversion point of the sunlit leaf fraction (see Fig. 4: $62^{\circ}$ solar zenith angle) is an effect of the slightly greater LAI of the average bracken individual. This also explains the fact that the shaded leaf area of bracken exceeds the shaded leaf area of Setaria at all solar elevations.

Summarizing Figs. 4 and 5 could suggest that Setaria receives more direct radiation around noon in comparison to bracken. However, the amount of PAR absorption is not

Table 2 Integrated optical traits (PAR) of Setaria sphacelata, bracken (Pteridium arachnoideum) and bare soil. (Source: field observations with HandySpec)

\begin{tabular}{llll}
\hline & Setaria & Bracken & Bare soil \\
\hline Reflectance (\%) PAR (400-700 nm) & 11.7 & 7.4 & 10.7 \\
Transmittance (\%) PAR (400-700 nm) & 1.5 & 3.7 & - \\
Absorptance (\%) PAR $(400-700 \mathrm{~nm})$ & 86.8 & 88.9 & 89.3 \\
\hline
\end{tabular}




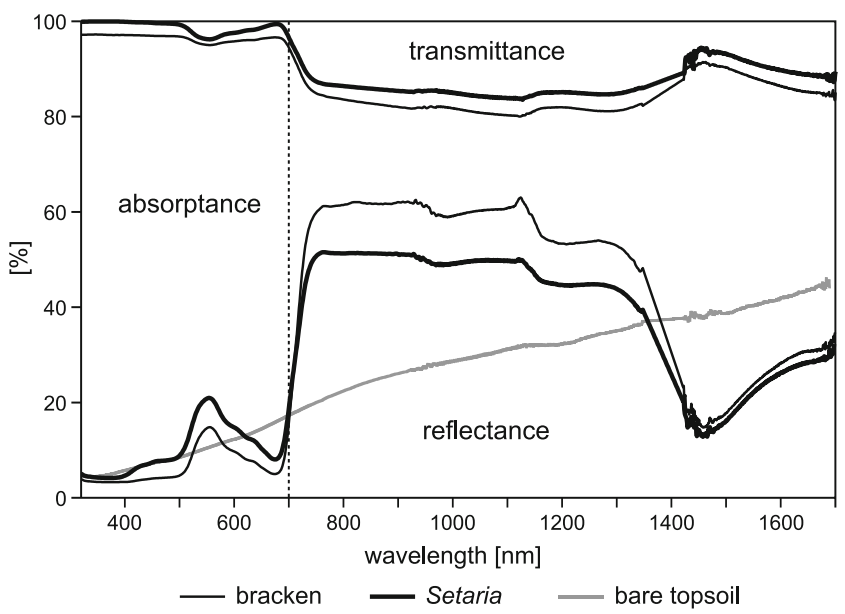

Fig. 3 Partitioning into reflectance (albedo), transmittance and absorptance of spectral radiation incident on Setaria sphacelata, Pteridium arachnoideum (as an average of three representative samples, LAI=1) and bare soil. The traced line represents the division between visible (PAR) and near infra red $(>700 \mathrm{~nm})$

only a function of sunlit and shaded leaf area but is strongly dependent on (1) the resulting angle of incidence on the leaves for direct beam radiation, (2) the relation of direct/ diffuse irradiance at the top of the canopy, and (3) the optical leaf traits. With regard to (1), a more perpendicular angle of incidence would be reached at low sun elevations for Setaria with its vertically oriented leaves when the sunlit leaf area is clearly reduced. In contrast, bracken shows the highest sunlit leaf area around noon when the solar rays are shining nearly perpendicular onto the horizontally oriented canopy fronds.

To address all governing factors (1-3) under realistic environmental conditions of the Rio San Francisco valley, a simulation was conducted which was initialized with the longterm averaged diurnal course of global irradiance (19982005) at the ECSF meteorological station (Fig. 1). The decomposition of global radiation was conducted by applying Eqs. 4-9. The results depicted in Fig. 6b clearly reveal that PAR absorption of bracken $\left(4.2 \mathrm{MJ} \mathrm{m}^{-2} \mathrm{day}^{-1}\right)$ is fairly equal to PAR absorption of Setaria $\left(4.5 \mathrm{MJ} \mathrm{m}^{-2}\right.$ day $^{-1}$.

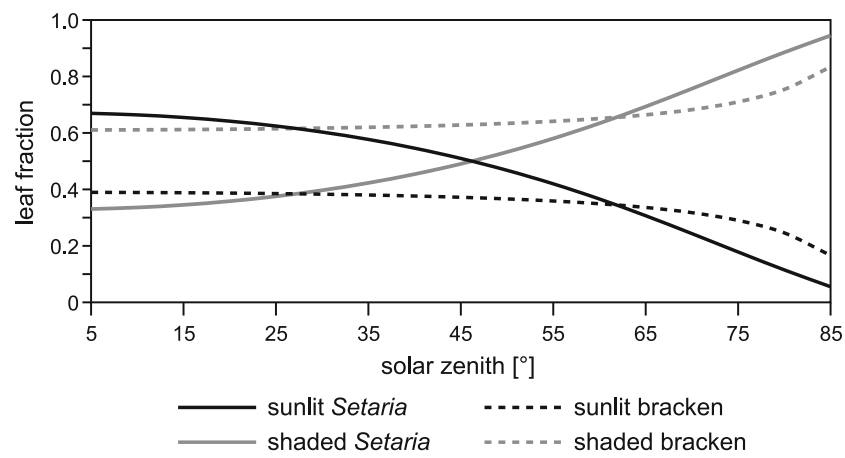

Fig. 4 Sunlit and shaded leaf fractions of bracken and Setaria for solar elevations between 5 and $85^{\circ}$ (solar elevation $=90^{\circ}$-solar zenith)

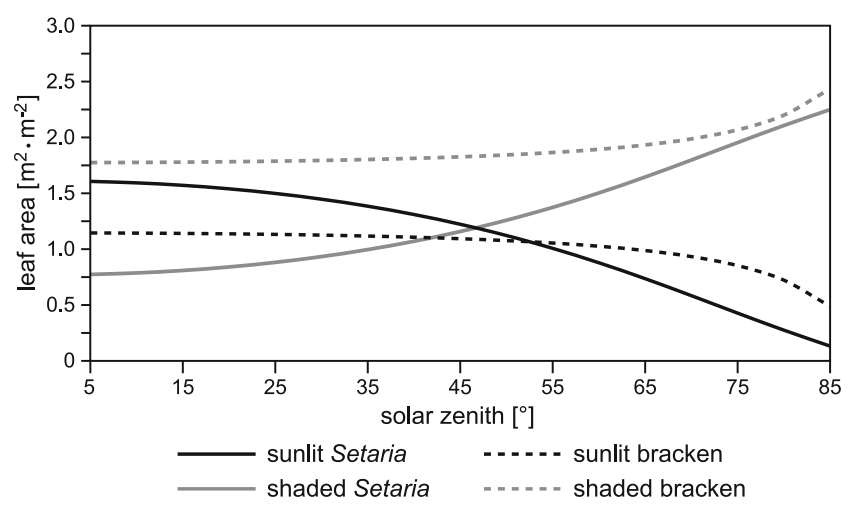

Fig. 5 Leaf area index $\left(\mathrm{m}^{2} \cdot \mathrm{m}^{-2}\right)$ of sunlit and shaded leaves of bracken and Setaria as depending on the solar zenith angle (solar elevation $=90^{\circ}$-solar zenith)

Integrated over the day, the difference ( $\triangle \mathrm{PAR}$ ) amounts to just $0.3 \mathrm{MJ} \mathrm{m}^{-2} \mathrm{day}^{-1}$. At first glance, this result is unexpected because considerable differences in sunlit and shaded leaf area of the two species exist (Fig. 6a).

a

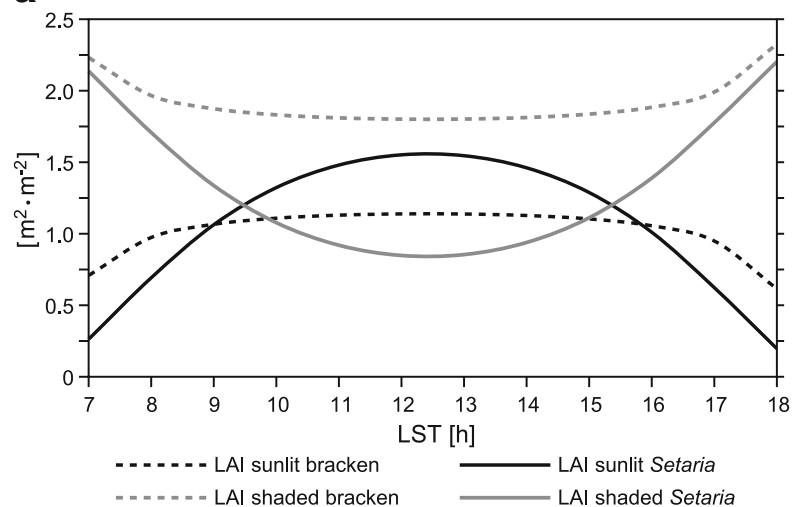

b

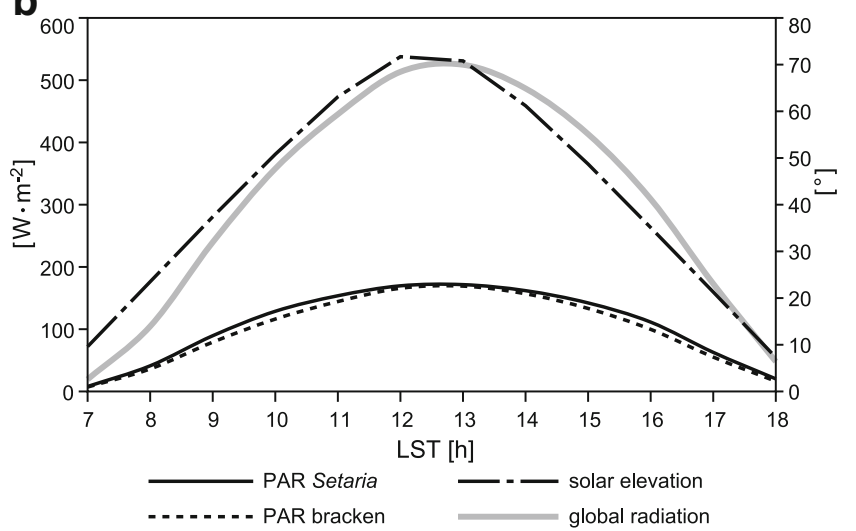

Fig. 6 a Leaf area indices $\left(\mathrm{m}^{2} \cdot \mathrm{m}^{-2}\right)$ of sunlit and shaded portions of the leaves of bracken and Setaria in the course of a day with regard to the average leaf-sun geometry of the study area. b Annual average of the diurnal course of irradiance at the ECSF meteorological station (1998-2005; Bendix et al. 2008a), sum of absorbed direct and diffuse PAR by sunlit and shaded leaves of bracken and Setaria plotted on the left ordinate axis and typical solar elevation in degrees on the right ordinate axis 
This effect is most likely the result of the predominantly diffuse solar radiation available in the San Francisco valley due to the high cloudiness. The reason is that the available direct radiation at an inclined surface (leaf), following Lambert's law, depends on the incident angle of the light beam as a combination of leaf angle and position of the sun, but this angular dependence is not applicable to isotropically distributed diffuse radiation. Consequently, the species-specific differences in sunlit and shaded leaf area are not as crucial as they should be under clear sky conditions. As a result, bracken can compensate for the lower fraction of sunlit frond area by its slightly higher absorption coefficient and the total LAI exceeding that of Setaria (Tables 1 and 2). Thus, the total radiation surplus of Setaria yields not more than $0.3 \mathrm{MJ} \mathrm{m}^{-2}$ day $^{-1}\left(4.2 \mathrm{MJ} \mathrm{m}^{-2}\right.$ day ${ }^{-1}$ bracken, $4.5 \mathrm{MJ} \mathrm{m}^{-2}$ day $^{-1}$ Setaria) in comparison to bracken over an average day in the Rio San Francisco valley.

To unravel the role of diffuse radiation on the PAR absorption potential, simulations were conducted for a typical sunny (5 December 2007) and cloudy (5 January 2008) day (Fig. 7).

The cloudy day with dominating diffuse irradiance reveals that Setaria has a slightly higher PAR absorption over the day $\left(2.1 \mathrm{MJ} \mathrm{m}^{-2}\right.$ day $\left.^{-1}\right)$ that exceeds that of bracken by $9.5 \%$ (or $0.2 \mathrm{MJ} \mathrm{m}^{-2}$ day $^{-1}$ ) (Fig. 7, right). However, it is striking that this potential growth advantage of Setaria is abolished during a sunny day with a great portion of direct solar irradiance around noon (Fig. 7, left). On such a day, bracken absorbs $8.5 \mathrm{MJ} \mathrm{m}^{-2}$ day $^{-1}$, which is $16.4 \%$ (or $1.2 \mathrm{MJ} \mathrm{m}^{-2} \mathrm{day}^{-1}$ ) more than total PAR absorption by Setaria. The reason of this inversion is illustrated in Fig. 8.

On sunny days, the major gain of PAR absorption by bracken as compared to Setaria is achieved by the absorption of incident direct beam radiation ( $I_{0}$ direct $)$ only. Here, the geometric configuration mentioned earlier takes effect. Fairly perpendicular incidence of the direct solar beam around noon (sun elevations $60-80^{\circ}$ ) onto nearly horizontally oriented bracken fronds provides the markedly higher direct radiation gain as compared to the nearly vertically oriented Setaria leaves. Even if PAR absorption of diffuse solar radiation $\left(I_{d 0}\right)$ and scattered diffuse radiation $\left(I_{d i f}\right)$ is higher for Setaria on the sunny day, this cannot compensate for the higher gain of direct beam PAR absorption by bracken fronds.

To test the PAR absorptance for different sunny and cloudy weather situations potentially occurring in the San Francisco valley, the ideal relative diurnal course of irradiance as measured on 5 December 2007 was taken
05 Dez 2007, clear day
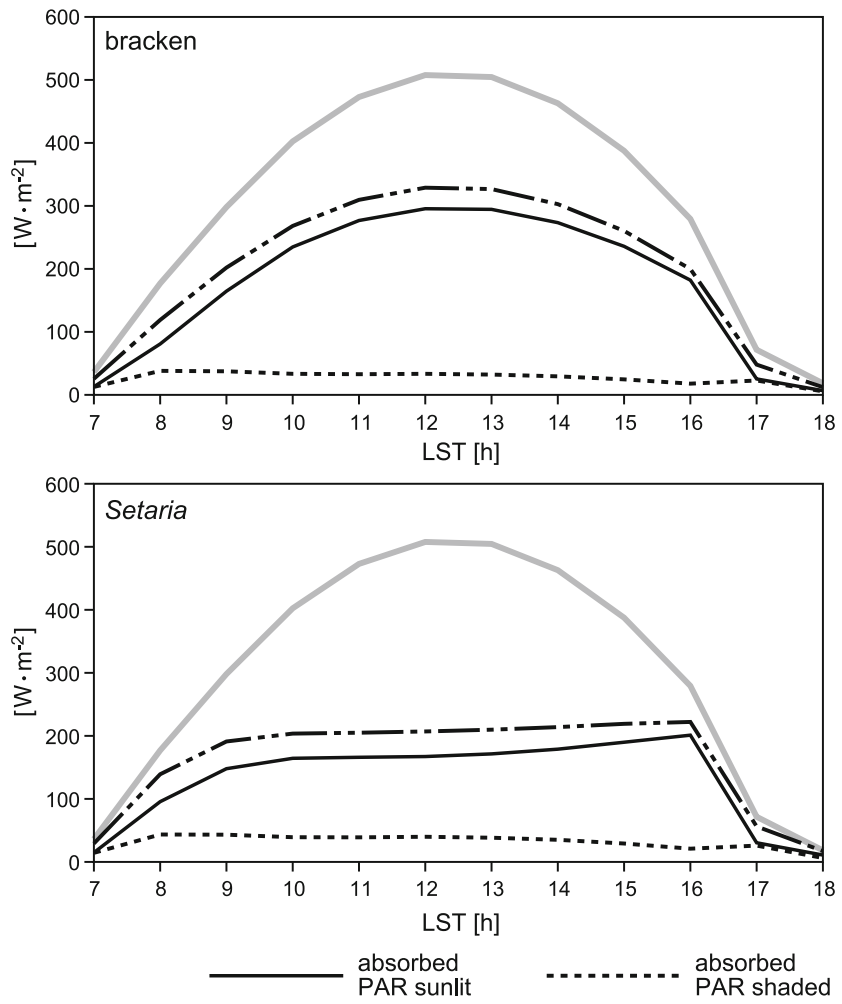

05 Jan 2008, overcast day
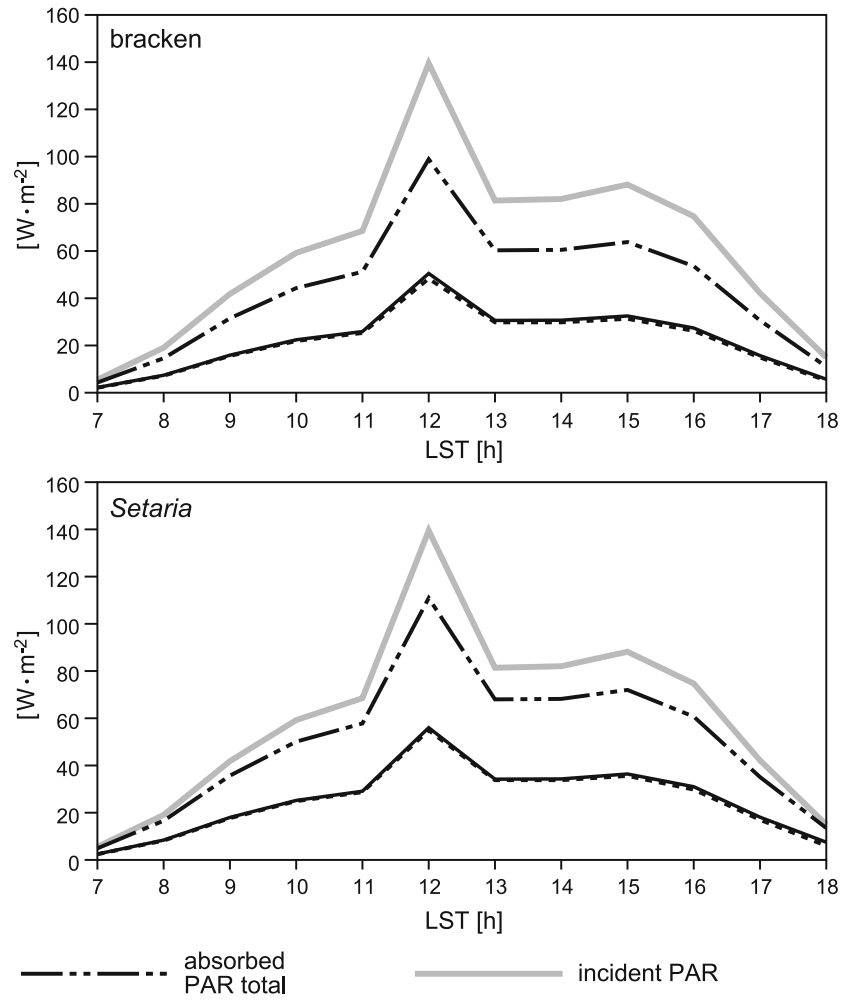

Fig. 7 PAR absorption of southern bracken and Setaria for (left) a sunny day (5 December 2007) and (right) a typical overcast day (5 January 2008). Radiation data for model initialization are taken from the micrometeorological station at the bracken experimental site (BS in Fig. 1) 

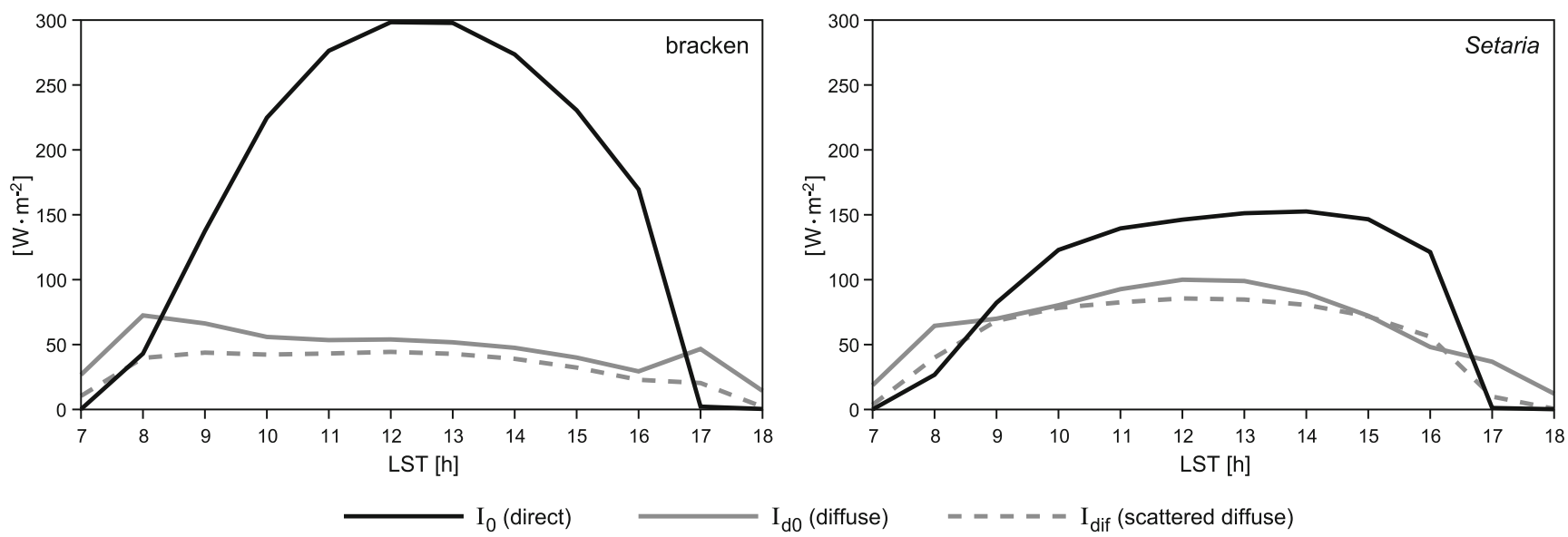

Fig. 8 Different PAR components absorbed by the sunlit canopy of bracken (left) and Setaria (right) on the sunny day (Fig. 7, left), 5 December 2007 , based on the radiative transfer scheme

and applied to incrementally increased daily radiation maxima ranging from 100 to $1,000 \mathrm{~W} \mathrm{~m}^{-2}$ (with an increment of $100 \mathrm{~W} \mathrm{~m}^{-2}$ ). Ten simulations were conducted with the radiation scheme based on the synthetically generated irradiation data. The decomposition of the generated diurnal data of global radiation by using Eqs. 4-9 leads to an increase of the direct radiation fraction with increasing radiation maximum. Consequently, a maximum of $100 \mathrm{~W} \mathrm{~m}^{-2}$ is mainly characterized by diffuse irradiance, a maximum of $1,000 \mathrm{~W} \mathrm{~m}^{-2}$ by a greater portion of direct solar irradiance. Figure 9 shows a clear speciesspecific distinction of PAR absorption capabilities due to varying radiation composition. Above a daily radiation maximum of about $615 \mathrm{~W} \mathrm{~m}^{-2}$ where direct radiation dominates, bracken absorbs clearly more direct PAR, as illustrated in Fig. 8 (direct PAR $\mathrm{I}_{0}$ ). The surplus of bracken PAR absorption is continuously increasing with increasing daily radiation maximum. Below the inversion point,

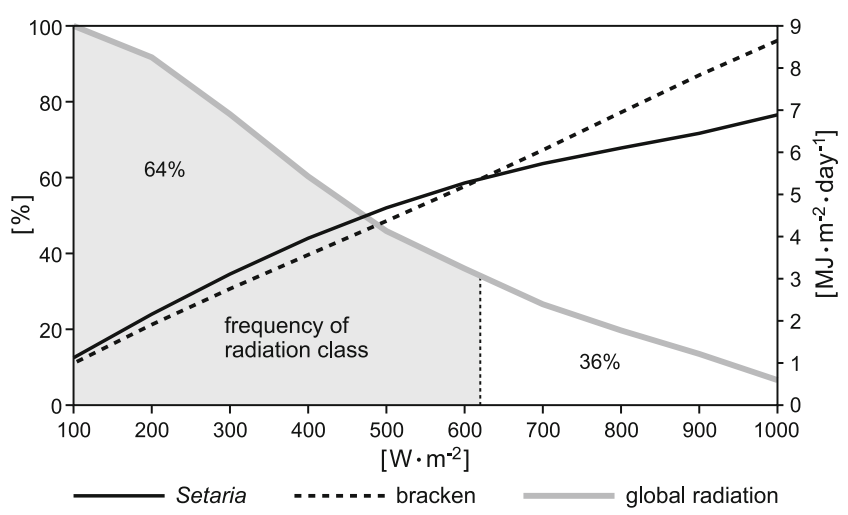

Fig. 9 Frequency and intensity of the daily irradiance maximum between 1200 and 1300 hours for the ECSF meteorological station (1998-2005) and total daily PAR absorption by bracken and Setaria, respectively, based on the relative diurnal course of radiation from 5 December 2007 (see Figs. 7 and 8)
Setaria shows a slight but nearly constant advantage in PAR absorption in comparison to bracken. In a next step, the hourly radiation data at the ECSF meteorological station from 1998-2005 were evaluated to derive the frequency of daily radiation maxima in the valley. Figure 9 reveals that illumination situations favoring Setaria PAR absorption occur on $64 \%$ of all days, while a third of all days with more direct radiation support the higher PAR absorption potential of bracken.

By summing up the daily PAR absorption based on the synthetically generated data over all days of the year, while considering the frequency distribution of the radiation classes in Fig. 9, yields no clear advantage of one of the both species. Setaria absorbs $1,533 \mathrm{MJ} \mathrm{m}^{-2}$ year $^{-1}$ PAR while bracken reaches almost the same annual PAR absorption capacity of $1,530 \mathrm{MJ} \mathrm{m}^{-2}$ year $^{-1}$.

\section{Discussion}

The current paper focuses on a comparison of the PAR radiation absorption capabilities of two competing species, the pasture grass Setaria sphacelata and an aggressive weed, the southern bracken (Pteridium arachnoideum), in the anthropogenic pasture system of a tropical mountain biodiversity hotspot in the eastern Andes of southern Ecuador. The work relies on a numerical two-big-leaf radiation scheme specifically parameterized with field surveys of plant functional traits, encompassing structural and optical parameters of both species. The samples selected during the field studies to derived plant functional traits were chosen to properly represent an average individual of both species under different growth situations (elevation, slope angle and aspect). The resulting structural and optical plant parameters are in good agreement with measured values for similar species or model defaults of comparable plant functional 
types (as, e.g., functional group of tropical $\mathrm{C} 4$ grasses). The average LAI of Setaria, for instance, coincides quite well with default values used for climate modeling of tropical C4 grasslands with land surface models (e.g., Buermann et al. 2001). The average LAI of southern bracken is lower than the maximum values for a fully developed canopy of northern bracken (P. aquilinum) in England (LAI 4 in late July; Blackburn and Pitman 1999; Pitman 2000). Leaf angle values for Setaria were similar to those reported by other studies of grasslands (e.g., Miller-Goodman et al. 1999; Peri et al. 2003). The average leaf angle distribution parameter for Setaria $(\chi=-0.37)$ is in the same order of the default value $(\chi=-0.3)$ supplied by a comparable radiation scheme for $\mathrm{C} 4$ grassland (Oleson et al. 2004). With regard to the optical traits, reflection measurements of bracken canopies in England (400-1,100 nm; Blackburn and Pitman 1999; Pteridium aquilinum) confirm the shape of the reflection curve, however with a slightly lower reflectance over the whole spectrum compared to the southern bracken. At the same time, transmittance in the visible and near infrared spectrum of bracken fronds in England (Pitman 2000) is somewhat higher in comparison to the southern bracken. Average measured PAR reflectance of Setaria is in almost perfect agreement with default values for $\mathrm{C} 4$ grasslands (11\%) provided by different studies (e.g., Fisch et al. 1995) and the CLM SVAT model that uses a similar radiation scheme as described in this study (Oleson et al. 2004). Even if the overall good coincidence indicates that the gathered field samples represent an average individual under average growth conditions in the study area, it should be stressed that plant parameters used in numerical models might even change with spatial resolution. This complicates the comparison of measured plant traits and respective published model parameters. By applying the parameterized radiation scheme, it is proven that the average individuals of bracken and Setaria have similar PAR absorption potentials under the typical radiation conditions of the Rio San Francisco valley. Comparable similarities were also found on the landscape level by other studies (e.g., Asner et al. 1998). The most important parameter for the determination of the fraction of absorbed PAR (fAPAR) in this study where the leaf area index of the Setaria and bracken average individuals is differing moderately $\left(\Delta \mathrm{LAI}=0.54 \mathrm{~m}^{2} \mathrm{~m}^{-2}\right)$ is the leaf-sun geometry (and thus, the leaf angle) in combination with the fractionation of the radiation components (direct, diffuse). Bracken has a higher PAR absorption potential under clear sky conditions because the leaf angle distribution favors PAR consumption during hours of high solar elevation. Similar directional effects are described for short grass ecosystem by Nouvellon et al. (2000). However, by scaling up to the landscape level, other authors stress that leaf area is the main decisive variable accounting for $60-80 \%$ of fAPAR variations while individually contributing canopy-level factors explain only a smaller proportion of fAPAR variations (Asner and Wessman 1997; Mwanamwenge et al. 1997; Asner et al. 1998).

With regard to the current state of the radiation scheme, the main uncertainty remains the decomposition of global radiation to its direct, diffuse, and PAR fractions. Comprehensive field observation of all radiation parameters is needed to derive a local decomposition function which can be implemented in the radiation scheme, replacing the currently used average decomposition functions (based on Eqs. 7-9). However, to derive local functions, several years (at least one) of diffuse radiation and PAR measurements are necessary. Most recently, respective sensors are installed and a preliminary comparison with 1 month of data and the results of the average functions used in this paper is conducted. With respect to diffuse radiation, $46 \%$ of values differ less than $10 \%$ of the calculated radiation where best results were reached for clear and completely overcast days. Generally, the average decomposition function (based on Eqs. 7-8 ) underestimates the observed values. With regard of PAR decomposition (based on Eq. 9), a slight overestimation by the function has been proven $(+12 \%$ on average). In most situations, this counterbalances the underestimation of the composition function for diffuse radiation so that the final calculation for incoming PAR radiation provides reasonable data for the radiation scheme. Nevertheless, locally derived decomposition functions replacing Eqs. 7-9 will be implemented when sufficient data have been gathered.

The results of the simulations gained with the parameterized radiation scheme reveal that neither bracken nor Setaria exhibit a clear advantage in PAR absorption capability under the current climatic conditions of the study area. This means that, at first glance, PAR absorption seems not to be the reason for bracken invasion. Another reason could be that the bracken plants have more biological growth power, e.g., due to the well-developed rhizome system which make them grow faster to get more PAR, water and nutrients. However, it must be stressed that radiation absorption is just the initial factor of plant growth. The transfer of absorbed PAR to biomass depends on the radiation use efficiency (RUE) that can exhibit great species-specific variations, particularly under water and nutrient stress (for bracken, refer, e.g., to Bray 1991 and Pakeman et al. 1994; for tropical C4 grass, to Kiniry et al. 1999 and Marques da Silva and Arrabaça 2004; for PAR absorption under fertilization, to Ostrowska et al. 2008). While water is not a limiting factor in the perhumid environment of the Rio San Francisco valley, nutrient deficiency (P, N) occurs (Makeschin et al. 2008). These effects will be tested in future research by using a photosynthesis module driven by the radiation scheme presented in this paper. 
Acknowledgements The authors gratefully acknowledge funding of the work by the German Research Foundation (DFG) in the scope of the DFG-Research Unit RU816 'Biodiversity and Sustainable Management of a Megadiverse Mountain Ecosystem in South Ecuador', subprojects C3.1, B3.1 and Z1.1. We further would like to thank Prof. Dr. Michael Richter (University of Erlangen-Nürnberg) for providing the data of the ECSF meteorological station that he collected in his subproject B1.4. B.Silva gratefully appreciates granting by the Brazilian Council of Technological and Scientific Development $(\mathrm{CNPq})$. The authors thank three anonymous reviewers for their valuable comments, which helped to improve the paper.

Open Access This article is distributed under the terms of the Creative Commons Attribution Noncommercial License which permits any noncommercial use, distribution, and reproduction in any medium, provided the original author(s) and source are credited.

\section{References}

Antunes MAH, Walter-Shea EA, Mesarch MA (2001) Test of an extended mathematical approach to calculate maize leaf area index and leaf angle distribution. Agr For Meteorol 108:45-53

Asner GP, Wessman CA (1997) Scaling PAR absorption from the leaf to landscape level in spatially heterogeneous ecosystems. Ecol Model 103:81-97

Asner GP, Wessman CA, Archer S (1998) Scale dependence of absorption of photosynthetically active radiation in terrestrial ecosystems. Ecol Appl 8:1003-1021

Barthlott W, Hostert A, Kier G, Koper W, Kreft H, Mutke J, Rafiqpoor MD, Sommer J (2007) Geographic patterns of vascular plant diversity at continental to global scales. Erdkunde 61:305-315

Beck E, Hartig K, Roos K (2008a) Forest clearing by slash and burn. In: Beck E, Bendix J, Kottke I, Makeschin F, Mosandl R (eds) Gradients in a tropical mountain ecosystem of Ecuador. Springer, Berlin, pp 371-374

Beck E, Makeschin F, Haubrich F, Richter M, Bendix J, Valerezo C (2008b) The ecosystem (Reserva Biologíca San Francisco). In: Beck E, Bendix J, Kottke I, Makeschin F, Mosandl R (eds) Gradients in a tropical mountain ecosystem of Ecuador. Springer, Berlin, pp 1-13

Bendix J, Homeier J, Cueva Ortiz E, Emck P, Breckle S-W, Richter M, Beck E (2006a) Seasonality of weather and tree phenology in a tropical evergreen mountain rain forest. Int $\mathrm{J}$ Biometeorol 50:370-384

Bendix J, Rollenbeck R, Göttlicher D, Cermak J (2006b) Cloud occurrence and cloud properties in Ecuador. Climate Res 30:133-147

Bendix J, Rollenbeck R, Fabian P, Emck P, Richter M, Beck E (2008a) Temporal heterogeneities - climate variability. In: Beck E, Bendix J, Kottke I, Makeschin F, Mosandl R (eds) Gradients in a tropical mountain ecosystem of Ecuador. Springer, Berlin, pp 281-290

Bendix J, Rollenbeck R, Göttlicher D, Nauß T, Fabian P (2008b) Seasonality and diurnal pattern of very low clouds in a deeply incised valley of the eastern tropical Andes (South Ecuador) as observed by a cost-effective WebCam system. Meteorol Appl 15:281-291

Bendix J, Rollenbeck R, Richter M, Fabian P, Emck P (2008c) Gradual changes along the altitudinal gradients - the climate. In: Beck E, Bendix J, Kottke I, Makeschin F, Mosandl R (eds) Gradients in a tropical mountain ecosystem of Ecuador. Springer, Berlin, pp 63-73

Blackburn GA, Pitman JI (1999) Biophysical controls on the directional spectral reflectance properties of bracken (Pteridium aquilinum) canopies: results of a field experiment. Int J Remote Sens 20:2265-2282
Boland J, Scott L, Luther M (2001) Modelling the diffuse fraction of global solar radiation on a horizontal surface. Environmetrics 12:103-116

Boland JW, Ridley B, Brown B (2008) Models of diffuse solar radiation. Renew Energy 33:575-584

Boulain N, Simoni G, Gignoux J (2007) Changing scale in ecological modelling: a bottom up approach with an individual based vegetation model. Ecol Model 203:257-269

Bray JR (1991) Growth, biomass, and productivity of a bracken (Pteridium esculentum) infested pasture in Marlborough Sounds, New Zealand. N Z J Bot 29:169-176

Brehm G, Homeier J, Fiedler K, Kottke I, Illig J, Nöske NM, Werne FA, Breckle SW (2008) Mountain rain forest in southern Ecuador as a hotspot of biodiversity - limited knowledge and diverging pattern. In: Beck E, Bendix J, Kottke I, Makeschin F, Mosandl R (eds) Gradients in a tropical mountain ecosystem of Ecuador. Springer, Berlin, pp 15-23

Buermann W, Dong J, Zeng X, Myneni RB, Dickinson RE (2001) Evaluation of the utility of satellite-based vegetation leaf area index data for climate simulations. J Climate 14:3536-3550

Cruz DR, Reyes ES, Sánchez JS (2009) Effects of meteorological factors on airborne bracken (Pteridium aquilinum (L.) Kuhn.) spores in Salamanca (middle-west Spain). Int J Biometeorol doi:10.1007/s00484-009-0208-5

Dai Y, Dickinson RE, Wang Y-P (2004) A two-big-leaf model for canopy temperature, photosynthesis, and stomatal conductance. J Climate 17:2281-2299

Dickinson RE (1983) Land surface processes and climate surface albedos and energy-balance. Adv Geophys 25:305-353

Elminir HK (2007) Experimental and theoretical investigation of diffuse solar radiation: data and models quality tested for Egyptian sites. Energy 32:73-82

Erbs DG, Klein SA, Duffie JA (1982) Estimation of the diffuseradiation fraction for hourly, daily and monthly-average global radiation. Sol Energy 28:293-302

FAO - Food and Agriculture Organisation (2001) Global forest resources assessment 2000 main report, FAO Forestry Paper 140. Rome, Italy

Fisch G, Wright IR, Bastable HG (1995) Albedo of a tropical grass: a case study of pre- and post-burning. Int J Climatol 14:103-107

Göttlicher D, Obregón A, Homeier J, Rollenbeck R, Nauß T, Bendix J (2009) Land cover classification in the Andes of southern Ecuador using Landsat ETM+data as a basis for SVAT modelling. Int J Remote Sens 30:1867-1886

Hartig K, Beck E (2003) The bracken fern (Pteridium aquilinum) dilemma in the Andes of South Ecuador. Ecotropica 9:3-13

Kiniry JR, Tischler CR, Van Esbroeck GA (1999) Radiation use efficiency and leaf $\mathrm{CO}_{2}$ exchange for diverse $\mathrm{C} 4$ grasses. Biomass Bioenergy 17:95-112

Lappi J, Stenberg P (1998) Joint effect of angular distribution of radiation and spatial pattern of trees on radiation interception. Ecol Model 112:45-51

Larocque GR (2002) Coupling a detailed photosynthetic model with foliage distribution and light attenuation functions to compute daily gross photosynthesis in sugar maple (Acer saccharum Marsh.) stands. Ecol Model 148:213-232

Lee R, Hernández-Andrés J (2005) Colors of the daytime overcast sky. Appl Optics 44:5712-5722

Maduekwe AAL, Chendo MAC (1994) Atmospheric turbidity and the diffuse irradiance in Lagos, Nigeria, 1994. ICTP Internal report IC/IR/94/141, Trieste, Italy

Makeschin F, Haubrich F, Abiy M, Burneo JI, Klinger T (2008) Pasture management and natural soil generation. In: Beck E, Bendix J, Kottke I, Makeschin F, Mosandl R (eds) Gradients in a tropical mountain ecosystem of Ecuador. Springer, Berlin, pp 397-408

Marques da Silva J, Arrabaça MC (2004) Photosynthesis in the waterstressed C4 grass Setaria sphacelata is mainly limited by stomata 
with both rapidly and slowly imposed water deficits. Physiol Plant 121:409-420

Marrs RH, Le Duc MG, Mitchell RJ, Goddard D, Paterson S, Pakeman RJ (2000a) The ecology of bracken: Its role in succession and implications for control. Ann Bot (Suppl B) $85: 3-15$

Marrs RH, Johnson SW, Le Duc MG (2000b) Control of bracken and restoration of heathland. VI. The response of bracken fronds to 18 years of continued bracken control or 6 years of control followed by recovery. J App Ecol 35:479-490

Miller-Goodman MS, Moser LE, Waller SS, Brummer JE, Reece PE (1999) Canopy analysis as a technique to characterize defoliation intensity on Sandhills range. J Range Manage 52:357-362

Mwanamwenge J, Siddique KHM, Sedgley RH (1997) Canopy development and light absorption of grain legume species in a short season Mediterranean-type environment. J Agron Crop Sci 179:1-7

Myneni BB, Asrar G, Hall FG (1992) A three-dimensional radiative transfer method for optical remote sensing of vegetated land surfaces. Remote Sens Environ 41:105-121

Nouvellon Y, Begue A, Susan Moran SM, Seen DL, Rambal S, Luquet D, Chehbouni G, Inoue Y (2000) PAR extinction in shortgrass ecosystems: effects of clumping, sky conditions and soil albedo. Agric For Meteorol 105:21-41

Oleson KW, Dai Y, Bonan G, Bosilovich M, Dickinson R, Dirmeyer P, Hoffman F, Houser P, Levis S, Niu G-Y, Thornton P, Vertenstein M, Yang Z-L, Zeng X (2004) Technical description of the Community Land Model (CLM). NCAR Technical Note NCR/TN-461+STR., Boulder, USA

Oliveira AP, Escobedo JF, Machado AJ, Soares J (2002) Correlation models of diffuse solar-radiation applied to the city of Sao Paulo, Brazil. Appl Energ 71:59-73

Ostrowska D, Pietkiewicz S, Cieslinski M, Kucinska K, Gozdowski D (2008) Biomass accumulation and absorption of photosynthetic active radiation by rapeseed plants depending on sulphur fertilization. World J Agricult Sci 4:133-136

Page CN (1986) The strategies of bracken as a permanent ecological opportunist. In: Smith RT, Taylor JA (eds) Bracken: ecology, land use and control technology. Parthenon, Carnforth, UK, pp 173-181

Pakeman RJ, Marrs RH, Jacob PJ (1994) A model of bracken (Pteridium aquilinum) growth and the effect of control strategies and changing climate. J Appl Ecol 31:145-154

Papaioannou G, Papanikolaou N, Retalis D (1993) Relationships of photosynthetically active radiation and shortwave irradiance. Theor Appl Climatol 48:23-27
Peri PL, Moot DJ, McNeil DL (2003) A canopy photosynthesis model to predict the dry matter production of cocksfoot pastures under varying temperature, nitrogen and water regimes. Grass Forage Sci 58:416-430

Pitman JI (2000) Absorption of photosynthetically active radiation, radiation use efficiency and spectral reflectance of bracken [Pteridium aquilinum (L.) Kuhn] canopies. Ann Bot 85:101-111

Pronk TE, During HJ, Schieving F (2007) Coexistence by temporal partitioning of the available light in plants with different height and leaf investments. Ecol Model 204:349-358

Richter M (2003) Using plant functional types and soil temperatures for eco-climatic interpretation in southern Ecuador. Erdkunde 57:161181

Roderick ML, Farquhar GD, Berry SL, Noble IR (2001) On the direct effect of clouds and atmospheric particles on the productivity and structure of vegetation. Oecologia 129:21-30

Schneider LC (2004) Bracken fern invasion in southern Yucatán: a case for land-change science. Geogr Rev 94:229-241

Sellers PJ (1985) Canopy reflectance, photosynthesis and transpiration. Int J Remote Sens 6:1335-1372

Thornton PE, Zimmermann NE (2007) An improved canopy integration scheme for a land surface model with prognostic canopy structure. J Climate 20:3902-3923

Tsubo M, Walker S (2005) Relationships between photosynthetically active radiation and clearness index at Bloemfontein, South Africa. Theor Appl Climatol 80:17-25

Wang Y-P, Leuning R (1998) A two-leaf model for canopy conductance, photosynthesis and partitioning of available energy I: model description and comparison with a multi-layered model. Agr For Meteorol 91:89-111

Wang Q, Tenhunen J, Schmidt M, Kolcun O, Droesler M, Reichstein M (2006a) Estimation of total, direct and diffuse PAR under clear skies in complex alpine terrain of the National Park Berchtesgaden, Germany. Ecol Model 196:149-162

Wang X, Guo Y, Li B, Wang X, Ma Y (2006b) Evaluating a three dimensional model of diffuse photosynthetically active radiation in maize canopies. Int $\mathrm{J}$ Biometeorol 50:349-357

Zhang X, Zhang Y, Zhoub Y (2000) Measuring and modelling photosynthetically active radiation in Tibet Plateau during AprilOctober. Agr For Meteorol 102:207-212

Zhang L, Moran MD, Brook JR (2001) A comparison of models to estimate in-canopy photosynthetically active radiation and their influence on canopy stomatal resistance. Atmos Environ 35:44634470 